\title{
Acardiac Twin: The Overlooked Diagnosis. A Recent Case Report and Review of Literature
}

\author{
Patrick Omondi Otieno ${ }^{1 *}$, Wycliffe Kosgei ${ }^{2}$ and Kibet Kibor Keitany ${ }^{2}$ \\ ${ }^{1}$ Department of Reproductive health, Moi University, Eldoret, Kenya \\ ${ }^{2}$ The Moi Teaching and Referral Hospital, Eldoret, Kenya \\ * Corresponding author: Patrick Omondi, Department of Reproductive health, Moi University, Eldoret, Kenya, Tel: +254 731226249 ;E- \\ mail:patrickomondi_md@yahoo.com
}

Received date:February26, 2020; Accepted date:March28, 2020; Published date:April03, 2020

Citation: Omondi P, Kosgei W, Keitany KK(2020) Acardiac Twin: The Overlooked Diagnosis. A Recent Case Report and Review of Literature.GyneObs Case Rep Vol.6 No.2: 90.

\section{Abstract}

Acardiac twin or Twin Reversed Arterial Perfusion sequence (TRAPS) is a unique and extreme complication seen in monochorionic multifetal pregnancies. It comprises an often normal twin pumping deoxygenated arterial blood in retrograde through an acardiac dysmorphic counterpart. Recently, a $2.6 \%$ incidence among monochorionic twins has been cited. For the pump/donor twin, mortality often exceeds $50 \%$ commonly from heart failure and prematurity. Acardiac twinning with a surviving donor twin has yet to be described in our setting. We describe a 28 year old para $0+1$ presenting in the second trimester with a twin pregnancy complicated by polyhydramnios of the donor viable twin and a non-viable recipient twin inadvertently diagnosed as a single fetal demise of a grossly malformed twin. The case was expectantly managed resulting in spontaneous preterm delivery and survival of the donor twin.TRAPS necessitates a high index of suspicion and a thorough sonographic evaluation in monochorionic multifetal pregnancies.

Keywords: Acardiac acephalus; Monochorionic twin; Twin reversed arterial perfusion sequence

\section{Introduction}

In twin pregnancies, approximately $20 \%$ are monozygotic and of these, $75 \%$ share a placenta. Most monochorionic twin pregnancies are characterized by varying degrees of anastomoses. Artery-artery anastomoses predominates in $75 \%$ of monochorionic placentas compared to vein-vein or arteryvein [1]. Consequently, the presence and persistence of a hemodynamic imbalance in the two fetal circulations may result in fetal-fetal transfusion disorders such as the twin reversed arterial perfusion sequence (TRAPS).

TRAPS or acardiac twinning is arguably the most extreme fetal-fetal transfusion disorder. Essentially, the often normal donor twin with a heart pumps blood through both fetal circulations. As such, mortality rate for the donor twin exceeds $50 \%$, more so without definitive management commonly from heart failure and prematurity [2]. Historically, the incidence of acardiac twin is about 1 in 35000 births averaging a 1\% risk in monochorionic twins[3]. Van Gemert recently cited an incidence of $2.6 \%$ in monochorionic twins on account of increased assisted reproductive technology and early cessation of acardiac development [4]. Several infrequent cases have been reported in West Africa. To our knowledge no cases of acardiac monochorionic twin pregnancy with a surviving donor twin have been described in literature in our setting.

\section{Case Report}

A 28 year old para $0+1$ Gravida 2 at $25+6$ weeks gestational age (GA) of a natural conception was admitted from our high risk clinic (HRC) where she had been on follow-up for chronic hypertension (HTN) diagnosed at 12 weeks GA with a twin pregnancy in which one was noted as nonviable and possibly vanishing. Her previous pregnancy resulted in fetal demise from early onset severe preeclampsia that she reports to have resolved post-delivery. At admission, the patient was on methyldopa, had no complaints, blood pressure (BP) was $118 / 78 \mathrm{mmHg}$. Ultrasonography revealed a twin pregnancy with a single placenta and diamniotic. Twin A was cephalic, viable, $891 \mathrm{~g}$ at 26 weeks with polyhydramnios but no gross anomalies. Twin B in breech with no cardiac activity had absent head and upper extremities at $23+1$ weeks by femur length. The spine, abdomen and lower limbs were appreciated. A diagnosis of chronic HTN with a single fetal demise of a grossly abnormal twin was made.

Upon admission the patient received dexamethasone, continued with methyldopa for 5 days after which it was stopped due to low BP's. Her BP remained normal thereafter. Maternal blood works, urinalysis and echocardiogram were normal. Delivery was planned for 32-34 weeks GA. Another obstetric scan 15 days later showed Twin A as viable, cephalic, $1314 \mathrm{~g}$ at $29+1$ weeks GA, amniotic fluid index of $24 \mathrm{~cm}$ with no gross anomalies. Twin B at 20 weeks was nonviable with absent head, neck and upper limbs. The abdomen, lower limbs and part of the thorax were visualized. Color flow Doppler sonography was however not performed. A week later the 
possibility of acardiac twin was considered subject to sonographic confirmation. The patient however went into spontaneous labour on the same day delivering vaginally a $1300 \mathrm{~g}$ male 1 st twin that scored 6/1, 8/5, 9/10 with no obvious gross congenital anomalies. He was admitted to newborn unit (NBU) due to the very low birth weight. The 2 nd twin was breech, macerated, 710g, with well-developed lower trunk and extremities but absent head, neck and upper extremities. Bilateral equino-varus deformity and underdeveloped external genitalia was also noted (Figure 1 \& 2).

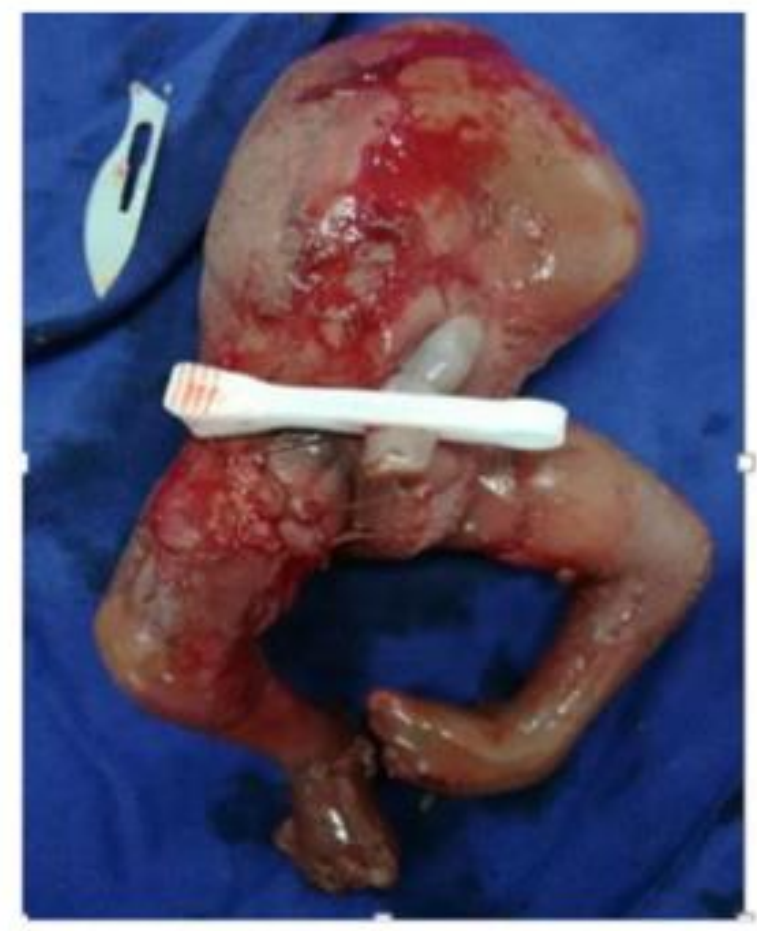

Figure 1:Macerated \& dysmorphic 2nd twin.

Grossly, the placenta was single and diamniotic. The first twin's cord was of normal length, with a central insertion (Figure 3). The dysmorphic twin had a short, thin cord with a membranous insertion (Figure4).

After counselling, the patient consented for autopsy on the suspected Acardius acephalus and a case write up. Autopsy confirmed absence of cranium, neck, upper limbs, liver, heart and spleen. The spinal column was incomplete terminating in the thoracic region (Figure 5 \& 6).

Histopathology showed a monochorionic diamniotic gestation and both twins had a 3 vessel cord (Figure 7 \& 8).

In NBU, the donor twin had a normal cranial ultrasound, a patent ductus arteriosus $(0.2 \mathrm{~cm})$ on echocardiogram and had complications of prematurity that were successfully managed as per our facility protocol. On day 40 of puerperium, upon weighing $1740 \mathrm{~g}$ the baby was discharged. Subsequently, the mother and baby remained healthy.

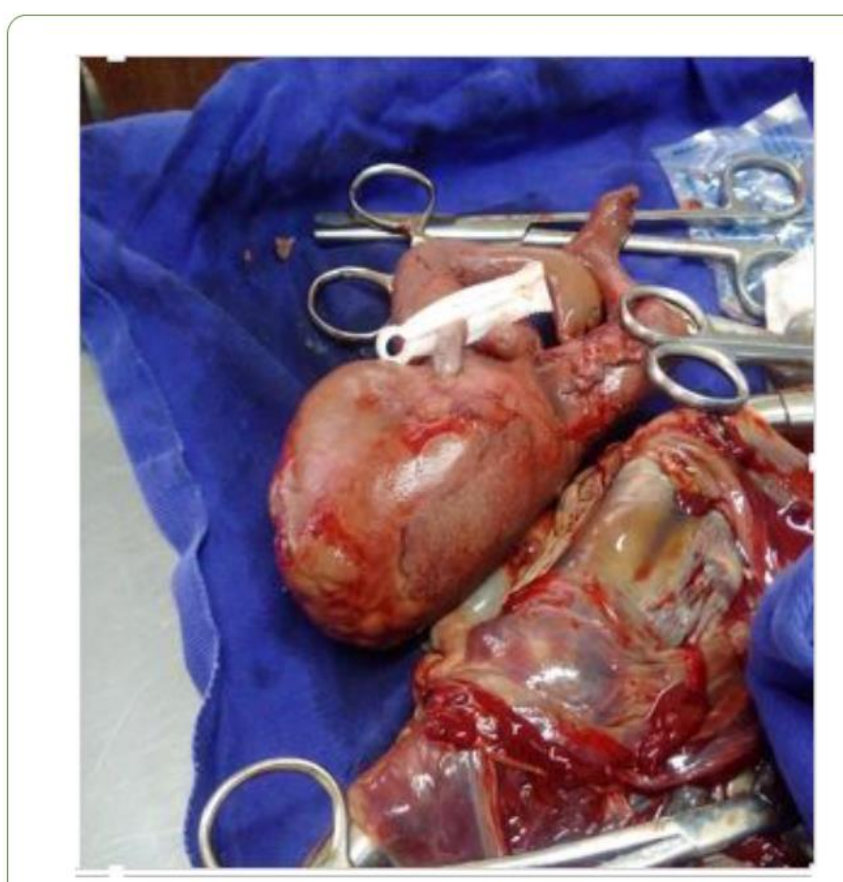

Figure 2: Absent head \& upper extremities on 2nd twin.

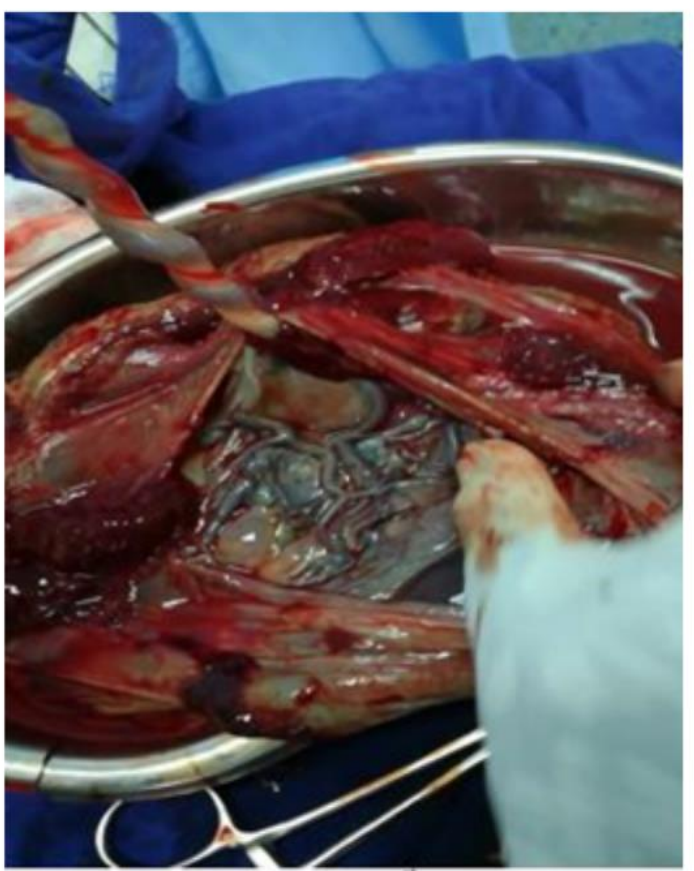

Figure 3: Central insertion for 1st twin's cord.

\section{Discussion}

Acardiac twinning is characterized by the presence of a fetus commonly without a heart with additional absence of other structures and another often normal pump twin. 


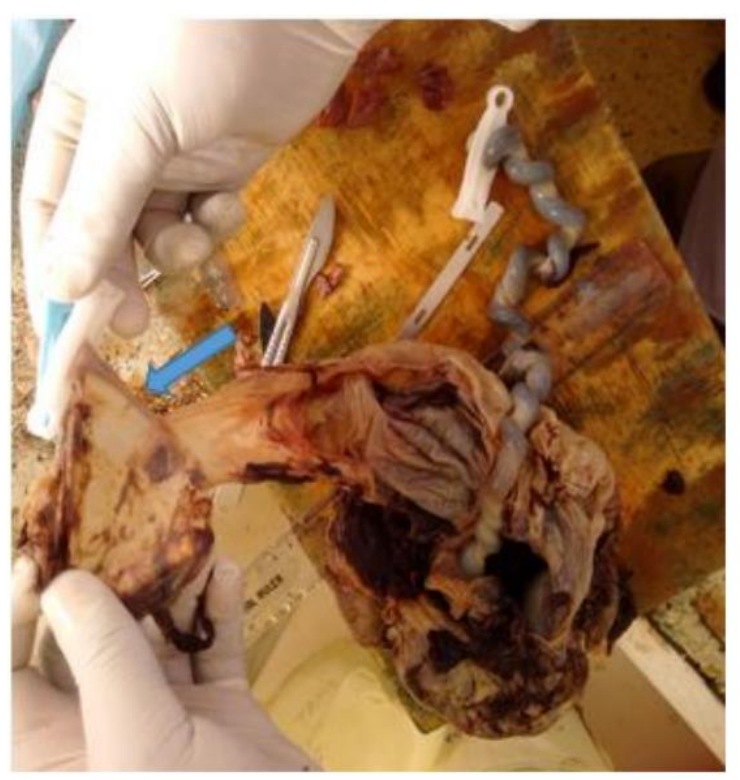

Figure 4: Membranous insertion for 2nd twin's cord.

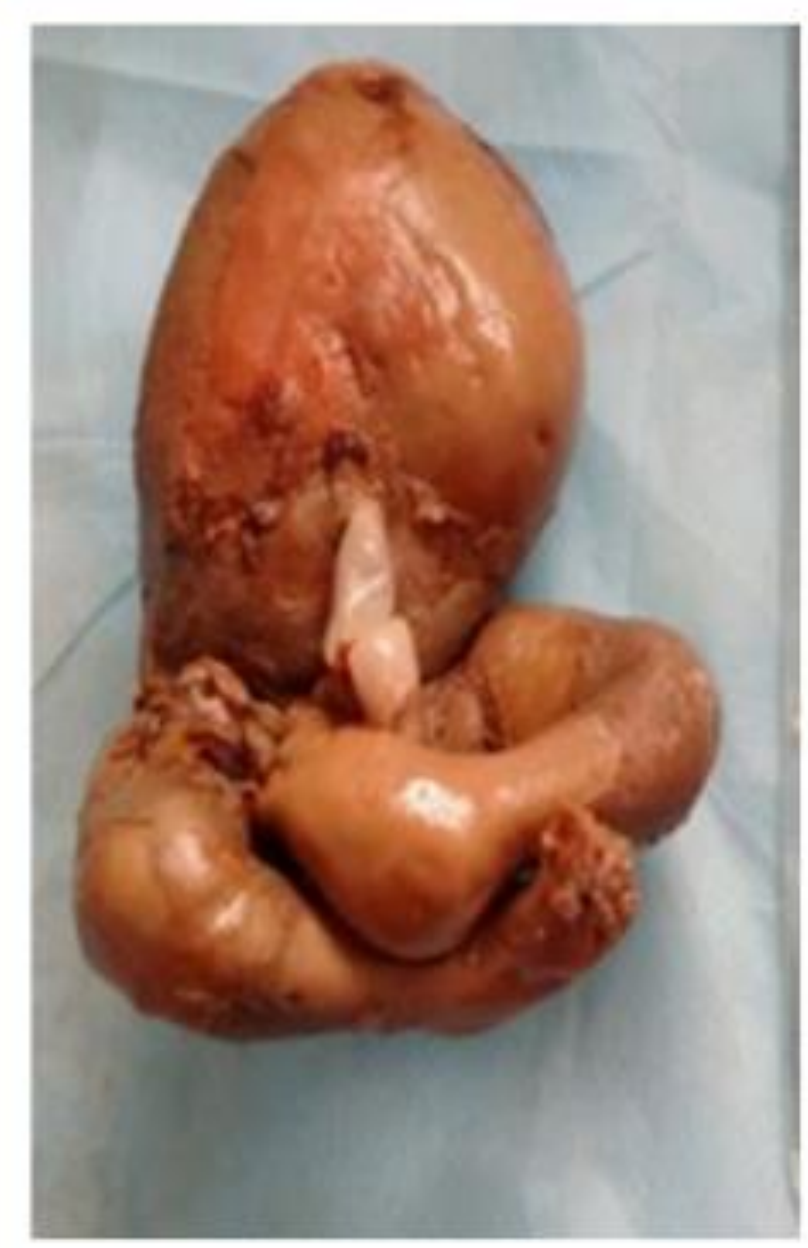

Figure 5: Acephalic 2nd twin with absent upper limbs.

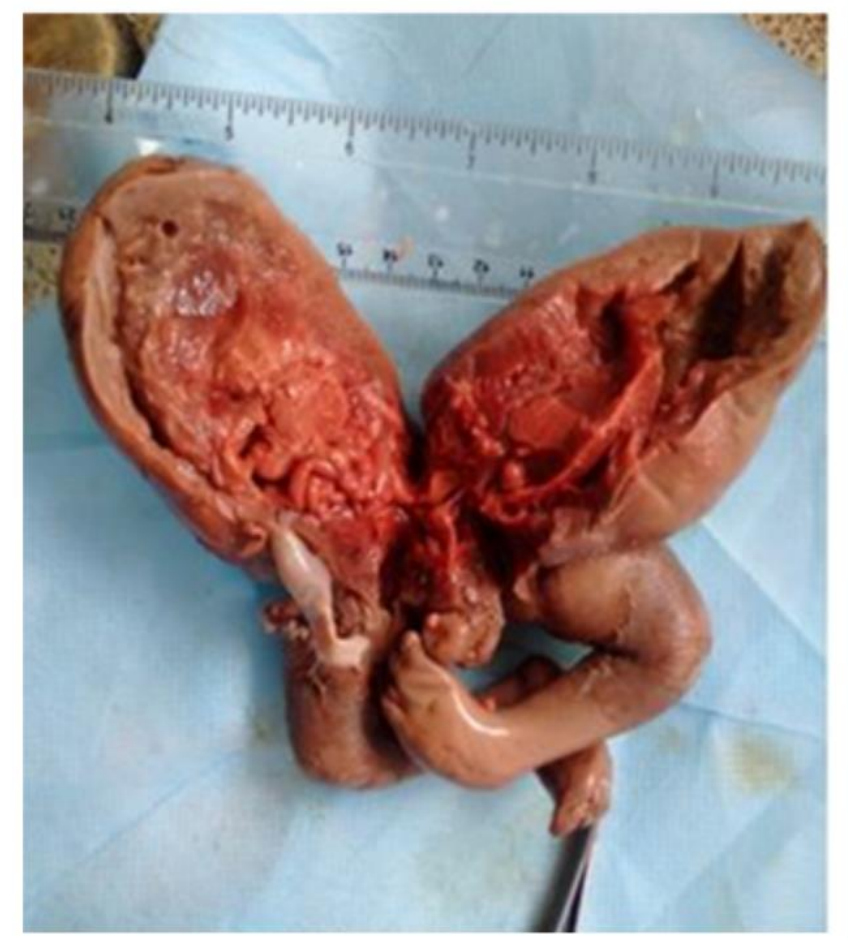

Figure 6: Autopsy of 2nd twin confirming acardi acacephalus.

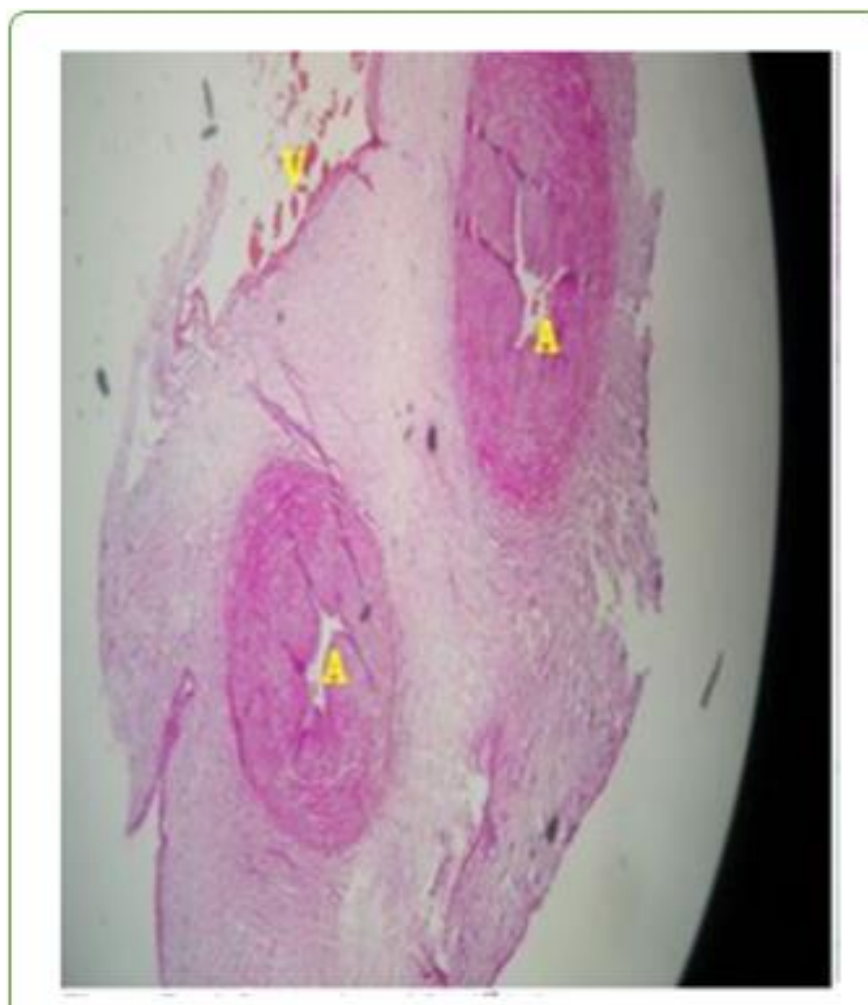

Figure 7: A 3 vessel cord for 1st twin. 


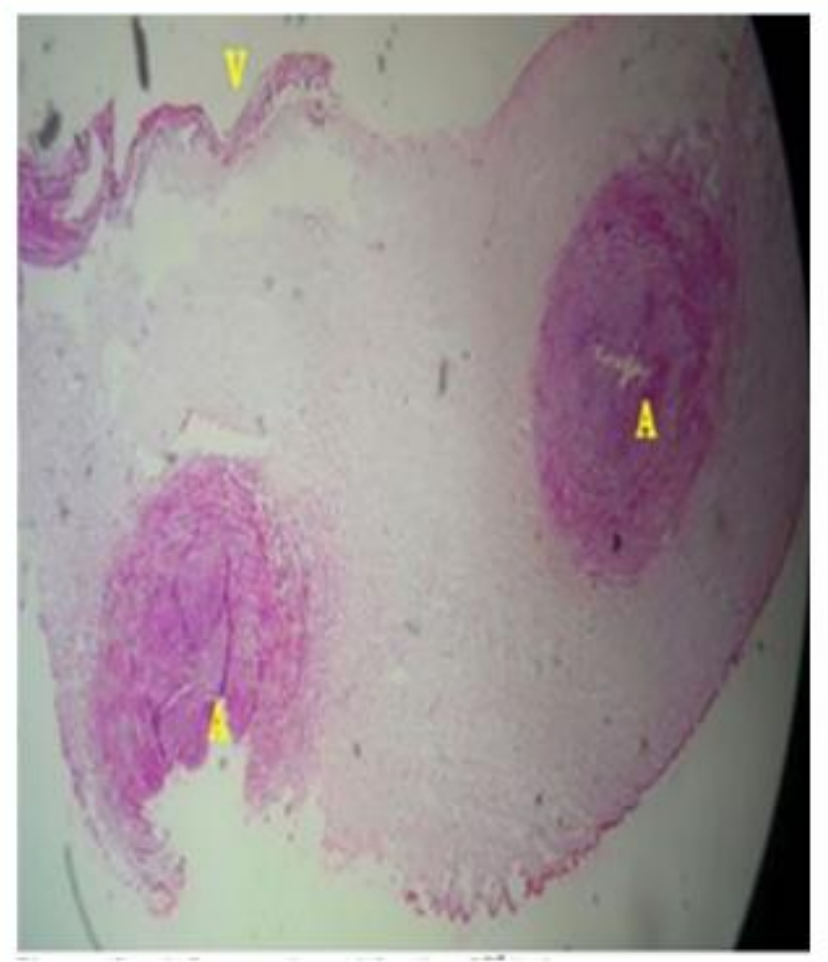

Figure 8: A 3 vessel cord for 2 nd twin.

It has been postulated that the existence of an artery-artery shunt occasionally accompanied by a vein-vein shunt within a single shared placenta may result in retrograde flow of deoxygenated arterial blood from the pump twin to the acardiac twin. Essentially, perfusion of the acardiac twin's umbilical circulation, aorta and vena cava is by reversed flow of deoxygenated blood resulting in early tissue hypoxia and atrophy of the heart and other organs. An alternative hypothesis proposes that a severe genetic or other primary defect sufficient to cause failure of cardiac development in one of the twins precedes the anastomotic connections and the reversed flow.

The various varieties of acardiac twin range from the most developed Acardius anceps to the least developed Acardius amorphous. Acardiac acephalus is however the commonest type where there is no cephalic development and often the upper extremities and neck are missing too as was seen in this case. The rare Acardius acormus and acardius myelacephalus have also been reported [5]. A 3 cord vessel is seen in a third of cases of acardiac twin with majority of these having abnormal insertions commonly on the membranes as was seen with this case [5].

Mortality for the acardiac twin is $100 \%$. For the donor twin, mortality and morbidity occurs in over half the cases due to heart failure, prematurity and chronic hypoxia from recirculation of deoxygenated blood via veno-venous anastomosis. Prognosis may be favourable with a high umbilical artery pulsatility index, non-rapid growth of the acardiac mass, good cardiovascular status of the pump twin, large differences in resistive index and a twin to twin weight ratio less than $50 \%$. $[2,6,7]$.

TRAPS should be suspected on sonography when a grossly malformed fetus is seen alongside a normal fetus in a monochorionic twin pregnancy with demonstration of retrograde blood flow in the dysmorphic twin on color flow doppler.Recurrence has not been documented and no maternal risk factor has overtly been associated with acardiac twinning.

Over half of cases with TRAPS diagnosed in first trimester may have spontaneous cessation of blood flow to the acardiac twin before $16-18$ weeks or later $[9,10]$. We believe this was so for our case. Therefore, conservative management with serial weekly sonographic surveillance is not unreasonable in select cases of a normal donor twin with favourable aforementioned prognostic indicators and limited resources for interventions.

This spontaneous cessation of blood flow may however result in subsequent death or neurological injury of the normal twin in over $60 \%$ of cases $[9,10]$.

Pagani et al found a reduction in adverse pregnancy outcomes when intervention was done preferably before 16 weeks compared with at or after 16 weeks or with conservative management [11]. Consequently some have advocated for prophylactic intervention rather than expectant management preferably at about 16 weeks $[8,11]$. Conversely, a metaanalysis of pregnancies treated at 12-27 weeks, found an inverse association between GA at treatment and GA at birth [10].

The ongoing "TRAPIST" trial (TRAP Intervention STudy), a multi-centre open-label randomized controlled trial to assess if early intervention (12.0-14.0 weeks) improves the outcome of TRAPS as compared to late intervention (16-18 weeks) is set to clarify this uncertainty.

For treatment, prenatal interruption of blood flow to the acardiac twin via intrafetal ablation techniques under ultrasound guidance is widely used and recommended as it is associated with a higher rate of clinical success and favourable outcomes than cord occlusion techniques $[8,11]$. Specifically, radiofrequency ablation or laser ablation of the acardiac twin's intra abdominal vessels may be used since either intrafetal methods have comparable survival rate of over $80 \%$ for the donor twin [9-11]. Preterm rupture of membranes remains the commonest post procedural complication.

More recently, the non-invasive High Intensity Focused Ultrasound (HIFU) has also been successfully used [12, 13]. Historically, maternal digoxin and indomethacin have also been used. Despite their limited role in modern practice, these may be considered in carefully selected patients who wish to keep their pregnancy in the setting of limited interventional resources or expertise. Ultimately, studies involving follow-up of the surviving donor twins are needed to objectively inform on possible adverse long term outcomes, if any, of intervention or lack thereof on the donor twin. 


\section{Conclusion}

As a unique and extreme complication, TRAPS necessitates a thorough clinical and sonographic evaluation as well as high index of suspicion in monochorionic multifetal pregnancies.

\section{Conflict of Interest}

The authors declare that there are no conflicts of interest. Acknowldgement

Sincerest appreciation to Dr. Moshey Issa, Dr. Mruttu Caroline, Dr. Li Ping and the Department of Reproductive Health, Moi University for their immense support.

This case was accepted for an e poster abstract presentation at the XXII FIGO World Congress 2018 and an earlier version of the abstract was published in the International Journal of Gynaecology and Obstetrics. (DOI: 10.1002/ijgo.12583).

\section{References}

1. Cunningham FG, Leveno KJ, Bloom SL, Spong CY, Dashe JS, et al. (2014) Multifetal pregnancy. In: Williams OBSTETRICS. 24th Edition. McGraw-Hill Education; 891-924.

2. Moore TR, Gale S, Benirschke K (1990) Perinatal outcome of forty-nine pregnancies complicated by acardiac twinning. Am J Obstet Gynecol. 163(3):907-912.

3. Gilim DL, Hendricks CH (1953) Holoacardius; review of the literature and case report. Obstet Gynecol. 2(6):647-653.

4. van Gemert M, van den Wijngaard J, Vandenbussche F (2015) Twin reversed arterial perfusion sequence is more common than generally accepted. Birth Defects Research Part A: Clinical and Molecular Teratology, 103: 641-643.
5. Roberto Ruiz-Cordero, Rhea JB, Liset $P$, Michel A,Maria MR (2016) Twin Reversed Arterial Perfusion Sequence (TRAPS): An Illustrative Series of 13 Cases. Fetal and Pediatric Pathology; $35: 2: 63-80$

6. Brassard M, Fouron JC, Leduc L, Grignon A, Proulx F (1999) Prognostic markers in twin pregnancies with an acardiacfetus. Obstet Gynecol. 94(3):409-414.

7. Dashe JS, Fernandez CO, Twickler DM (2001) Utility of Doppler velocimetry in predicting outcome in twin reversed-arterial perfusion sequence. Am J Obstet Gynecol. 185(1):135-139.

8. Mone F, Devaseelan P, Ong S (2015) Intervention versus a conservative approach in the management of TRAP sequence: a systematic review. J Perin Med, 44(6):619-629.

9. Lewi L, Valencia C, Gonzalez E (2010) The outcome of twin reversed arterial perfusion sequence diagnosed in the first trimester. Am J ObstetGynecol 203:213.e1-4.

10. Chaveeva P, Poon LC, Sotiriadis A, Kosinski P, Nicolaides $\mathrm{KH}$ (2014) Optimal method and timing of intrauterine intervention in twin reversed arterial perfusion sequence: Case study and meta-analysis. FetalDiagnTher. 35(4):267-279.

11. Tan T, Sepulveda W (2003) Acardiac twin: a systematic review of minimally invasive treatment modalities. Ultrasound ObstetGynecol, 22: 409-419.

12. Okai T, Ichizuka K, Hasegawa J (2013) First successful case of non-invasive in-utero treatment of twin reversed arterial perfusion sequence by high-intensity focused ultrasound. Ultrasound ObstetGynecol, 42: 112-114.

13. Ichizuka K, Hasegawa J, Nakamura M (2012) High-intensity focused ultrasound treatment for twin reversed arterial perfusion sequence. Ultrasound ObstetGynecol, 40: 476-478. 